\title{
4 LA VIDA INTERIOR COMO DIMENSIÓN CLAVE EN LA COMPRENSIÓN DE LA PERSONA SEGÚN EDITH STEIN
}

DOI: $10.22199 / 507198175.2010 .0001 .00004$

\section{María Teresa GREENE}

\section{Resumen}

El presente trabajo aborda algunos elementos centrales del pensamiento de Edith Stein sobre la persona en Ser finito y ser eterno, considerando la vida interior como clave de comprensión de la misma. El acercamiento a esta dimensión más profunda del ser humano se realiza mediante el análisis de la estructura de la persona y su relación con Dios. La interioridad de la persona se revela en este estudio como un mundo complejo que se puede recorrer y profundizar hasta llegar a su más profundo centro, aquel que define al hombre. En ese mundo interior la persona, gracias a su espíritu, se encuentra con el mundo exterior, consigo misma y con Dios.

Palabras claves: Persona, cuerpo, alma, espíritu, interioridad.

\section{INTERIOR LIFE AS A KEY DIMENSION IN THE UNDERSTANDING OF THE PERSON ACCORDING TO EDITH STEIN}

\begin{abstract}
This paper concerns certain central elements of the thought of Edith Stein about the person as a finite being and eternal being, considering interior life as the key for understanding the human person. The approach to this most profound dimension of the human being is done through the analysis of the structure of the person and his or her relationship with God. The interior life of the person is revealed in this study as a complex world to be explored until one has discovered its center, that part that defines the person. In this interior world of the person, thanks to his spirit, he or she encounters the exterior world, the self and God.
\end{abstract}

Key words: Person, body, soul, spirit, interior life. 


\section{Introducción}

El presente trabajo contempla una aproximación al pensamiento de Edith Stein sobre la persona en Ser finito y ser eterno. Ensayo de una ascensión al sentido del ser', obra en que esta autora desarrolla ampliamente la cuestión del "ser-persona".

En su investigación de las leyes fundamentales que rigen el ser y la vida espiritual, su atención se fija especialmente en las cuestiones relacionadas con la esencia y el destino de la persona humana, teniendo como horizonte la imagen de la Trinidad en la creación y de manera especial en el hombre. A lo largo de este texto, Edith Stein tiene en mente la pregunta por el sentido y fundamento del ser humano, que se basa en la relación con el ser divino y tiene por modelo a Cristo.

Los presupuestos filosóficos y antropológicos que acompañan su comprensión de la persona son decisivos. Aquí cabe mencionar que la posición filosófica original de la autora se formó mediante el diálogo con Husserl y con santo Tomás de Aquino. Sus obras principales son un intento de filosofar con el método fenomenológico, que afirma la voluntad de ir a las cosas mismas. La fenomenología le permitió desarrollar, a partir de la experiencia, una reflexión que termina reencontrando la ontología, aunque va más allá de ella, manteniéndose fiel a la exigencia moderna de partir del hombre más bien que del ente o de alguna categoría abstracta.

Dentro de este contexto esbozaremos algunas líneas centrales sobre la estructura de la persona a partir de su interioridad tal como Edith Stein la concibe en Ser finito y ser eterno. El acercamiento a esta dimensión más profunda del ser humano, tanto femenino como masculino, se hará mediante la siguiente pregunta: ¿en qué medida la noción de vida interior en Ser finito y ser eterno posibilita la comprensión del ser-persona del hombre?

1 STEIN Edith, Endliches und Ewiges Sein. Versuch eines Aufstiegs zum Sinn des Seins (Edith Stein Gesamtausgabe, 11/12), Herder, Freiburg-Basel-Wien, 2006. Traducción castellana: Ser finito y ser eterno. Ensayo de una ascensión al sentido del ser (Obras completas, Vol. III: Escritos filosóficos. Etapa de pensamiento cristiano: 1921-1936), Burgos, 2007. 


\section{EL SER PERSONA}

\section{El ser del yo y el ser eterno}

Ser finito y ser eterno es sin duda la obra maestra de Edith Stein y como tal nos proporciona la clave para entender su pensamiento en la etapa de madurez espiritual$^{2}$. En este estudio la autora se propone una doble finalidad: "La búsqueda del sentido del ser y el esfuerzo de fusionar el pensamiento medieval con el vivo pensamiento contemporáneo"3. Ella quiere hacer confluir el lenguaje y el pensamiento de diferentes corrientes filosóficas en un único cauce para que puedan comprenderse mutuamente ${ }^{4}$.

Al inicio, el texto se concentra en dos nociones fundamentales: el ser en potencia y el ser en acto. Luego se amplía al ser finito y al ser eterno. La dinámica que se da en entre estos dos aspectos a lo largo de la obra nos permite conectarlos en una relación ascendente que va del ser finito hacia el ser eterno.

Como punto de partida de su investigación, Edith Stein, al igual que san Agustín, Descartes y Husserl, se fija en el hecho del propio ser, es decir, en el propio yo. Se trata aquí, ante todo, no de un yo abstracto, sino de un yo vivo. Para ella la certeza del propio ser es una certeza "no reflexionada", pues se da antes de todo pensamiento sobre la propia existencia ${ }^{5}$. En efecto, "el ser eterno y el ser temporal, el inmutable y el mutable, e igualmente el no-ser son ideas que el espíritu descubre en sí mismo; no están tomadas de otra parte" ${ }^{6}$. La autora piensa que una filosofía basada en el conocimiento natural tiene aquí un punto de partida legítimo. “También la analogia entis, considerada como la relación entre el ser temporal y el ser eterno,

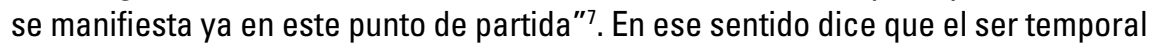
no es pleno ser porque es sólo para un momento; su fragilidad se encuentra en el ser momentáneo. El ser finito es un "analogon" del ser eterno, el cual es inmutable

2 Ser finito y ser eterno surgió en 1936 de la revisión de Potencia y acto como un tratado totalmente nuevo, constituyendo la obra de mayor relieve entre los escritos filosóficos de Edith Stein. Sin embargo, el trabajo no llegó a publicarse durante su vida. Cf. HERBSTRITH W., El verdadero rostro de Edith Stein, Madrid, Ediciones Encuentro, 1990, p. 121; STUBBEMANN C.M., La mujer en Edith Stein: antropología y espiritualidad, Burgos, Publicaciones de la Facultad de Teología del Norte de España, 71, 2003, pp. 61-62.

3 STEIN E., Ser finito y ser eterno, p. 605.

4 Cf. STEIN E., op. cit., pp. 615-616.

5 Cf. STEIN E., Ser finito y ser eterno, pp. 645-646; STUBBEMANN C.M., op. cit., p. 62.

6 STEIN E., op. cit., p. 647.

7 Ibid., p. 647. 
y por esta razón es el ser pleno en cada instante; "es una 'imagen' que tiene semejanza con el arquetipo, pero que ofrece más desemejanza"8.

La fenomenóloga afirma que la vida del yo "depende, por sus contenidos, de un 'doble más allá', de un 'mundo exterior' y de un 'mundo interior' que se manifiestan en la vida consciente del yo, en esa esfera del ser que es inseparable del yo" ${ }^{\prime \prime}$. El ser del yo es temporal, es algo que vive de momento en momento y no llega jamás verdaderamente a poseerse a sí mismo. "Por eso estamos obligados a designar el ser del yo, este presente continuamente cambiante, como una cosa recibida. Está puesto en la existencia y allí está conservado de un instante al otro"10.

De esta manera, nuestra autora constata que el propio ser de la persona es limitado y sin fondo, pero que al mismo tiempo la persona es mantenida en el ser: " $\mathrm{Mi}$ ser, tal como yo lo encuentro y tal como yo me encuentro en él, es un ser nulo; yo no existo por mí mismo y por mí mismo nada soy, me encuentro a cada instante ante la nada y tengo que recibir el don del ser momento tras momento. Y sin embargo, este ser vano o nulo es sery por eso toco a cada instante la plenitud del ser"11. La inmediatez del propio ser finito remite, por tanto, constantemente a "la idea del ser verdadero, del ser eterno e inmutable"12, que se convierte en norma del propio ser. Más aún, la reflexión sobre la propia finitud y fugacidad confronta al hombre con su inseguridad existencial, pero también con el hecho de que "a pesar de esta fugacidad, soy y soy conservado en el ser de un instante al otro; en fin, en mi ser fugaz, yo abrazo un ser duradero. Yo me sé sostenido y este sostén me da tranquilidad y seguridad; ciertamente no es la confianza segura de sí misma del hombre que, con su propia fuerza, se mantiene de pie sobre un suelo firme, sino la seguridad dulce y feliz del niño que reposa sobre un brazo fuerte... En mi ser yo me encuentro entonces con otro ser que no es el mío, sino que es el sostén y el fundamento de mi ser que no posee en sí mismo ni sostén ni fundamento"13.

¿Cómo llega el hombre a reconocer en el ser que le sustenta al ser eterno, es decir, a Dios? Según Edith Stein esto es posible mediante dos vías. Un acceso a ese fundamento lo constituye la fe, que se apoya en la experiencia de Dios que se re-

\footnotetext{
8 Ibid., p. 647.

9 Ibid., p. 663.

10 Ibid., p. 664.

11 Ibid., p. 664.

12 Ibid., p. 665.

13 Ibid., p. 667.
} 
vela personalmente. Esto significa que el hombre sólo puede adherirse a Dios si ha sido aprehendido por él previamente ${ }^{14}$. Otro acceso lo da el conocimiento filosófico, que es el conocimiento racional ${ }^{15}$. Esta vía permite trabajar con conceptos claros, pero no puede conceder al hombre la certeza última que le da la fe: “El camino de la fe nos conduce al Dios personal y cercano, al amante y al misericordioso y nos da una certeza que no se encuentra en ninguna parte en el conocimiento natural. Sin embargo, también el camino de fe es un camino oscuro. Dios mismo baja el tono de su lenguaje a la medida del hombre a fin de volver asible al inasible" 16 .

Partiendo en primer lugar del propio ser, la autora descubre que éste se manifiesta "como un ser fugaz que pasa de un instante a otro" y considera que no se puede pensar "sin otro ser fundado en sí mismo y creador, dueño de todo ser, que es el ser mismo"17. Luego analiza las diversas formas de ser en los distintos niveles de la realidad, contrastando la metafísica aristotélico-tomista con la perspectiva fenomenológica, para mostrar la unión y dependencia de todo ser finito respecto del ser eterno, lo cual le permite presentar una visión íntegra y coherente del universo. De este modo, Edith Stein llega a Dios como principio e imagen originaria de todo ser finito y en cuanto tal como sentido del $\operatorname{ser}^{18}$.

\section{El ser en persona}

Siguiendo la concepción agustiniana según la cual Dios manifiesta en el "Yo soy" su propio nombre, Edith Stein interpreta la expresión "Yo soy el que soy" de la siguiente manera ${ }^{19}$ : “Aquel cuyo nombre es 'Yo soy' es el ser en persona. El que el así llamado 'ente primero' tiene que ser persona se puede deducir de lo mucho que antes hemos dicho: sólo una persona puede crear, es decir, llamar a la existencia en virtud de su propia voluntad." 20 .

Para la fenomenóloga el ser persona humana va ligado al nombre divino. De hecho "el nombre gracias al cual cada persona se designa sí misma en cuanto tal,

\footnotetext{
14 Cf. op. cit., p. 667; STUBBEMANN C.M., op. cit., p. 63.

15 Cf. STEIN E., op. cit., pp. 667-668.

16 STEIN E., op. cit., p. 669; cf. STUBBEMANN C.M, op. cit., p. 63.

17 STEIN E., op. cit., p. 713.

18 Cf. op. cit., cc. III-VI; STUBBEMANN C.M., op. cit., p. 63.

19 Cf. STEIN E., op. cit., pp. 940-941.

20 STEIN E., op. cit., p. 941; cf. c. II, § 7.
} 
es 'yo'. Sólo puede llamarse 'yo' un ente que en su ser es consciente de su propio ser y a la vez de su ser diferente, distinto de todo otro ente. Cada yo es algo único y posee algo que no comparte con ningún otro ente, es decir, algo 'incomunicable' (el significado tomista de individualidad)... Lo incomunicable que forma parte de cada 'yo' en cuanto tal, constituye una particularidad del ser. a cada uno brota su ser, que llamamos vida, le brota de instante en instante y se realiza en un ente $c e$ rrado en sí, y, cada uno a su manera está ahí para sí mismo como para ningún otro ente y como ningún otro ente está ahí para él" ${ }^{21}$. Cada hombre es un yo y la vida del yo es su ser, "pero no se identifica con el ser del hombre"22, aclara la autora. Una distancia infinita lo distingue del ser divino, "sin embargo, le es más semejante que cualquier otra cosa que forme parte del campo de nuestra experiencia: precisamente porque es un yo, una persona... No existe en Dios -como en el hombre- una contraposición entre la vida del yo y el ser. Su 'yo soy' es un presente eternamente vivo, sin comienzo ni fin, sin lagunas y sin obscuridad. Este yo viviente posee en sí y por sí toda plenitud; no recibe nada de otra parte: es la fuente de donde todas las demás cosas reciben lo que poseen; condiciona toda otra cosa y él mismo es el incondicionado" 23 .

El ser que es autor y arquetipo de todo ser finito "se revela a nosotros como el ser en persona y más aún, como el ser en tres personas"24. De ahí que Edith Stein se pregunte: "Si el Creador es el arquetipo de la creación, ¿no se debe encontrar en la creación una imagen, aunque lejana, de la unidad trinitaria del ser originario? Y por lo tanto, ¿no sería posible llegar a la comprensión más profunda del ser finito?" ${ }^{25}$. En su respuesta ella sostiene que la imagen de la Trinidad en la creación desemboca y culmina en la imagen de Dios en el hombre: en cuanto ser espiritual-personal y en cuanto hombre como tal. Dice al respecto: "Por persona hemos entendido el soporte de la esencia y especialmente el soporte de una naturaleza dotada de razón. El hecho de poseer la razón distingue a la persona de la hipóstasis en cuanto soporte de la esencia en sentido amplio"26. Aquí la autora aclara la distinción y la relación de este soporte con el yo: “Hemos llamado al 'yo' soporte de su vida: es aquello de lo que brota la vida interior ('vida interior' en cuanto contraposición a lo

\footnotetext{
21 STEIN E., op. cit., p. 941.

22 Ibid., p. 942.

23 Ibid., p. 942.

24 Ibid., p. 951.

25 Ibid., p. 951.

26 Ibid., p. 957.
} 
que se 'manifiesta' en la configuración material de los llamados 'seres vivos'); es lo que vive en esta vida y la experimenta como suya... Hay por consiguiente una vida del yo, y un correspondiente 'ser consciente' que no es un comprender y un entender de sí mismo"27 en el sentido estricto de una captación conceptual. "Pero se llama dotada de razón a una criatura que puede comprender la normalidad de su ser propio y según esto puede orientarse con su comportamiento. Además, corresponde el entendimiento como don de comprensión y la libertad como el don de configurar por sí mismo el propio comportamiento. Si el hecho de poseer la razón pertenece al ser persona, entonces la persona en cuanto tal debe tener entendimiento y libertad. Llegamos así a la separación del yo y de la persona: no cada yo debe ser necesariamente un yo personal. Al contrario, toda persona debe ser un yo: es decir, ser consciente de su ser propio, puesto que esto pertenece a la dotación de la razón"28. De esta manera, "si pertenece al yo como tal el que su vida brote de él y que experimente esta vida como la suya propia, entonces el yo personal debe poder además comprender su vida y configurarla libremente desde sí mismo. Así comprendemos que Dios, quien en su libertad perfecta configura su propia vida y que es enteramente luz (al que no hay nada escondido), debe ser persona en el sentido más elevado. Puesto que la vida personal es un salir desde sí y al mismo un ser y un permanecer en sí mismo, pero ambos aspectos caracterizan la esencia del espíritu, por eso el ser personal es igualmente un ser espiritual" ${ }^{29}$.

\section{ESTRUCTURA DE LA PERSONA Y VIDA INTERIOR}

\section{Cuerpo vivo, alma y espíritu}

Como ya hemos visto, Edith Stein no parte de una teoría determinada acerca del hombre, sino de la persona misma tal como "la tenemos ante nuestros ojos en la experiencia viva" ${ }^{30}$. Según ella, cada persona participa de una triple condición: la del ser humano, la de la especie y la de su individualidad personal. No se trata de diferentes etapas o niveles que la persona hubiese de recorrer, sino de tres condiciones que se dan en una sola persona: la naturaleza humana se verifica en una configuración femenina o masculina e individua ${ }^{31}$.

\footnotetext{
27 Ibid., p. 958.

28 Ibid., p. 958.

29 Ibid., p. 958.

30 STEIN E, La estructura de la persona humana, Madrid, BAC, 1998, p. 50.

31 Cf. STUBBEMANN C.M., op. cit., p. 69.
} 
El marco principal de su antropología se mantiene en todos sus escritos: la persona humana constituye una unidad de cuerpo vivo, alma y espíritu ${ }^{32}$, y es como tal un ser en constante desarrollo. En Ser finito y ser eterno ella afirma claramente que en esta unidad tripartita se encuentra la imagen de Dios uno y trino: "La triple forma dinámica del alma debe considerarse como una unidad trinitaria, pero también lo que ella configura: cuerpo-alma-espíritu. Si tratamos de comparar esta unidad trinitaria con la unidad divina, así veremos en el alma, en cuanto elemento de fuente que se nutre de sí misma y se configura en cuerpo vivo y en espíritu, la imagen del Padre, en el cuerpo vivo en cuanto expresión de una esencia netamente delimitada veremos la imagen del Verbo eterno, y en la vida espiritual la imagen del Espíritu divino"33.

Nuestra autora concibe al hombre como un microcosmos, el cual reúne en sí los diferentes estadios que se dan en el reino del ser: "es cosa material, ser vivo, ser animado y persona espiritual" ${ }^{34}$. En cuanto persona espiritual, está abierta hacia dentro y hacia fuera. Esta apertura radical la confronta inexorablemente también con la pregunta por el ser absoluto y el sentido último de su existencia ${ }^{35}$. "En cuanto el hombre es espíritu según su esencia, sale de sí mismo con su 'vida espiritual' y entra en un mundo que se le abre, sin perder nada de sí mismo. 'Exhala no sólo su esencia -como toda hechura real- de una manera espiritual expresándose él mismo de modo inconsciente: además actúa personal y espiritualmente. El alma humana en cuanto espíritu se eleva en su vida espiritual por encima de sí misma. Pero el espíritu humano está condicionado por lo que le es superior e inferior: está inmerso en un producto material que él anima y forma en vista de su configuración de cuerpo vivo. La persona humana lleva y abarca 'su cuerpo vivo' y 'su' alma, pero es al mismo tiempo soportada y abarcada por ellos"36.

Edith Stein insiste en la unidad corporal-anímico-espiritual. Sin embargo, eso no significa que estos tres elementos estén en un plano de igualdad. Hay una clara subordinación del cuerpo al espíritu ${ }^{37}$.

32 Los términos que usa la autora son: Leib, Seele y Geist.

33 STEIN E., Ser finito y ser eterno, op. cit., p. 1051.

34 STEIN E, La estructura de la persona humana, op. cit., p. 52; cf. Ser finito y ser eterno, op. cit., p. 963.

35 Cf. STEIN E., La estructura de la persona humana, op.cit., pp. 55-56; Ser finito y ser eterno, op. cit., p. 965.

36 STEIN E., Ser finito y ser eterno, op, cit., pp. 959-960.

37 Cf. STUBBEMANN C.M., op. cit., pp.70-71. 
El cuerpo humano comparte con los demás cuerpos la materialidad, pero se diferencia de ellos por su libre automovimiento, su sensibilidad y su vinculación a un sujeto concreto. El cuerpo humano está animado desde un centro interior (forma o alma), que organiza su funcionamiento a través de una regularidad interior y una jerarquización de los estadios del ser, en virtud de la cual lo inferior queda siempre sometido a lo superior (lo vegetal a lo animal y éste a lo humano-espiritual). El hombre se percibe en su cuerpo, es decir, a cada cuerpo corresponde un yo, y se percibe con su cuerpo. Por tanto, no sólo tiene un cuerpo, sino que es su cuerpo. El cuerpo hace de puente entre el mundo interior de la persona humana y el mundo exterior. Gracias a él el hombre entra en contacto con lo que le rodea y es capaz de intervenir eficazmente en el mundo. Además, la persona expresa su vida interior a través del cuerpo. De esta manera, la autora establece una conexión importante entre la vida anímico-espiritual de la persona y su cuerpo, conexión que no admite considerarlo como un mero objeto, ya que esto llevaría fácilmente a un dualismo, tan ajeno a su antropología ${ }^{38}$.

El hombre comparte con el animal su estructura psicofísica, es decir, su cuerpo animado por un alma sensitiva. Pero la persona no sólo siente, sino que se siente, "toma conciencia de sí, se caracteriza por la receptividad para los valores y es capaz de penetrar el mundo y de intervenir libre y creativamente en él. La persona humana está, por tanto, dotada de un alma espiritual y del espíritu"39.

Lo que caracteriza a un sujeto como persona es precisamente su alma espiritual ${ }^{40}$. El alma es "el centro de todo ese edificio físico-psíquico-espiritual que llamamos "hombre" 41 , y como tal le confiere unidad. Creada directamente por Dios, el alma es imagen del Espíritu divino ${ }^{42}$, única, individual e inmortal ${ }^{43}$. Su estructura personal indica la existencia de un yo consciente y libre en virtud del cual el hombre "puede abrir y cerrar sus puertas" ${ }^{44}$. Donde la vida anímica propia está formada

38 Cf. STEIN E., Ser finito y ser eterno, op. cit., pp. 960-965; STUBBEMANN C.M., op. cit., pp. 73-75.

39 STUBBEMANN C.M., op. cit., p. 78; cf. STEIN E., Ser finito y ser eterno, op. cit., p. 965; La estructura de la persona humana, op. cit., pp. 51-52.

40 Cf. STUBBEMSANN C.M., op. cit., pp. 78-79.

41 STEIN E., El castillo interior (Obras completas, Vol. V: Escritos espirituales. En el Carmelo Teresiano: 1933-1942), Burgos, 2004, p. 80; cf. Ser finito y ser eterno, op. cit., pp. 1010-1011.

42 Cf. STEIN E., El castillo interior, op. cit., p. 100.

43 Cf. STEIN E., Ser finito y ser eterno, op. cit., p. 1090.

44 STEIN E., La estructura de la persona humana, op. cit., p. 141; cf. Ser finito y ser eterno, op. cit., p. 965. 
personalmente, allí la naturaleza espiritual está plenamente realizada: “Por eso el alma humana no sólo es un intermedio entre el espíritu y la materia, sino que es también una criatura espiritual, no sólo una hechura o formación del espíritu, sino también un espíritu configurante"45.

El cuerpo está completamente penetrado por el alma, de manera que no sólo la materia organizada se convierte en cuerpo penetrado de espíritu, sino que también el espíritu se convierte en espíritu materializado y organizado. Hay, por tanto, una orientación del hombre sensitivo al hombre espiritual, lo que implica que el cuerpo le es dado al hombre como materia para su formación ${ }^{46}$. La persona, dueña de sí misma, es la que, haciendo uso correcto de su libertad, integra de tal manera su dimensión psicofísica que ésta no impide su crecimiento espiritual. De ahí que el concepto de unidad implique el de la autodeterminación de la persona humana, en cuanto que el hombre está llamado a la plenitud y depende en parte de su libre autoeducación si llega o no a la meta, que es la génesis plena de la persona humana ${ }^{47}$.

\section{Alma e interioridad}

Edith Stein piensa que la naturaleza espiritual del alma tiene una triple tarea: la autoconfiguración como desarrollo de su propia esencia, la formación del cuerpo y la elevación por encima de sí misma a la unión con Dios ${ }^{48}$. De ahí que el alma se caracterice al mismo tiempo por una doble condición: su vinculación esencial al cuerpo y su autonomía en cuanto espíritu ${ }^{49}$. "La división tradicional tripartita de cuerpo-alma-espíritu no debe entenderse como si el alma del hombre fuese un tercer reino entre otros dos, pero sin ellos e independientemente de ellos. En ella misma espiritualidad y sensibilidad coinciden y están entrelazadas entre sí... El hombre no es ni animal ni ángel, puesto que es los dos en uno. Su sensibilidad como cuerpo vivo es diferente de la del animal y su espiritualidad es diferente de la del ángel"50. "Siente y experimenta lo que se hace en el cuerpo y con él, pero este sentir es una percepción consciente y destinada a llegar a ser una percepción comprensiva del cuerpo vivo y de los procesos corporales, así como de una per-

45 STEIN E., Ser finito y ser eterno, op. cit., p. 1017.

46 Cf. op. cit., pp. 963-965.

47 Cf. op. cit., pp. 1017-1023; STUBBEMANN C.M., op. cit., p. 71.

48 Cf. STEIN E., Ser finito y ser eterno, op. cit., pp. 1047-1048 y 1050.

49 Cf. STUBBEMANN C.M., op. cit., p. 79.

50 STEIN E., Ser finito y ser eterno, op. cit., p. 966. 
cepción de lo que 'cae bajo los sentidos', del mundo exterior. La percepción es ya conocimiento, un hacer espiritual" 51 .

El alma es la forma bajo la cual se hace presente el espíritu en el cuerpo. En cuanto sustancia espiritual, es una forma subsistente, pero por su orientación hacia el cuerpo, una sustancia que necesita ser complementada, que sólo es perfeccionada por el cuerpo ${ }^{52}$. "El alma es el 'espacio' en medio de todo lo corporalanímico-espiritual; en cuanto alma sensible, habita en el cuerpo vivo, en todos los miembros y partes, recibe de él y obra sobre él configurándolo y manteniéndolo" ${ }^{53}$; en cuanto alma espiritual, ella trasciende más allá de sí misma y mira un mundo situado más allá de su propio yo -un mundo de cosas, de personas, de sucesos-, un mundo con el que entra en relación y del cual recibe ${ }^{54}$. "Pero en cuanto alma en el sentido más propio, habita en sí misma, y en ella el yo personal está como en su propia casa. Aquí se reúne todo lo que proviene del mundo de los sentidos y del espíritu, aquí surge la disputa interna con ellos; desde aquí tiene lugar la toma de posición, y de aquí se gana lo que llegará a ser su propiedad personal, parte consciente de sí misma"55. De esta manera, por su peculiaridad de ser un espíritu encarnado, el alma cumple la función de "mediación entre la espiritualidad y sensibilidad propia del cuerpo vivo"56.

La particularidad del alma, para Edith Stein, "consiste en ser el propio núcleo del ser vivo y la fuente escondida de donde toma su ser para aparecer como figura visible"57. "La vida interior es aquí un ser consciente, el yo un ser despierto, cuyo ojo espiritual mira hacia el interior y hacia el exterior: puede asumir comprendiendo todo lo que va hacia él, responder en una libertad personal, de tal o cual manera. Lo puede y porque lo puede, el hombre es una persona espiritual, soporte de su vida en el sentido eminente del personal 'tener en la mano'. Sin embargo, no hace uso de su libertad en toda la extensión, sino que se abandona en gran medida a los 'sucesos' $y$ a las 'tendencias' como un ser sensible. Y en efecto, es ser sensible, incapaz de configurar toda su vida en una acción libre" 58 .

51 Ibid., p. 966.

52 Cf. STUBBEMANN C.M., op. cit., pp. 79-80.

53 STEIN E., Ser finito y ser eterno, op. cit., p. 967.

54 Cf. op. cit., p. 967.

55 STEIN E., Ser finito y ser eterno, op. cit., pp. 967-968.

56 Ibid., p. 966; cf. op. cit., p. 1047.

57 Ibid., p. 964.

58 Ibid., p. 965. 
El alma en cuanto centro de la persona es concebida como lugar, por sus dimensiones de profundidad y superfici ${ }^{59}$ : “El alma, como 'castillo interior', tal como la describe nuestra santa madre Teresa, no es a modo de punto como el 'yo puro', sino un 'espacio' - un 'castillo' con muchas moradas- donde el yo puede moverse libremente saliendo o retirándose más al interior" ${ }^{10}$. Tanto en Ser finito y ser eterno como en El castillo interiory en la Ciencia de la cruz, Edith Stein asocia ese "lugar" con la imagen del "castillo del alma", que está tomada de la obra Castillo interior de santa Teresa de Jesús. Este lugar es el recinto más personal del sujeto humano, donde mora el yo personal. Pero nuestra autora no identifica, sin más, el yo con el alma como tal, aunque deja claro que no puede haber alma humana sin un yo ni viceversa ${ }^{61}$. Dentro del "espacio" del alma, el yo, como un "punto" móvil, se desplaza libremente, yendo hacia afuera y recogiéndose en el interior ${ }^{62}$. "A pesar de su movilidad, el yo está siempre ligado a aquel inmóvil punto central del alma en el cual se siente en su propia casa"63.

Para la fenomenóloga, “lo 'interior y más íntimo' es también lo más espiritual', lo más alejado de la materia, lo que mueve el alma en su profundidad"64. "La interioridad más profunda del alma es lo 'más espiritual en ella"65.

Según Edith Stein, la comprensión tiene lugar en esta profundidad y puesto que toda la fuerza espiritual vive ahí, la comprensión penetra en todo lo que se relaciona con ella. "Se trata de un pensar en que se encuentra comprometido 'el hombre entero'... La razón de esto es que 'piensa con el corazón'. El corazón es el verdadero centro de la vida. Designamos así el órgano corporal cuya actividad gobierna la vida del cuerpo" ${ }^{66}$. Dado que se suele entender por el corazón la interioridad del alma, "seguramente es el corazón el que participa más fuertemente en lo que pasa en el fondo del alma, ya que ahí es donde se puede percibir más claramente la conexión del cuerpo y del alma que en ninguna otra parte"67.

59 Cf. op. cit., pp. 967 y 1022; STUBBEMANN C.M., op. cit., p. 84.

60 Cf. STEIN E., op. cit., pp. 968 y 1022.

61 Cf. op. cit., pp. 968-969; STUBBEMANN C.M., op. cit., pp. 84-85.

62 Cf. STEIN E., El castillo interior, op. cit., p. 105; Ser finito y ser eterno, op. cit., p. 968.

63 STEIN E., El castillo interior, op. cit., p. 105; cf. Ser finito y ser eterno, op. cit., pp. 967 y 1022-1023.

64 STEIN E., Ser finito y ser eterno, op. cit., p. 972.

65 Ibid., p. 1029.

66 Ibid., p. 1026.

67 Ibid., p. 1026. 
"En el interior es donde la esencia del alma irrumpe hacia adentro"68. De esta interioridad más profunda "resulta también la irradiación de la propia esencia, el involuntario salir espiritual de sí misma. Mientras más recogido está el hombre en lo más profundo de su alma, tanto más poderosa es esta irradiación que mana de él y atrae a otros a su círculo. Pero tanto más marcado lleva también todo comportamiento libre espiritual la señal de la particularidad personal que se sitúa en la interioridad más profunda del alma. Además el cuerpo está más fuertemente impregnado de ella y por ello mismo 'espiritualizado'. Aquí se encuentra el verdadero centro del ser corporalanímico-espiritual" ${ }^{\prime 9}$. Por lo tanto, el centro del alma coincide con la esencia de la persona, con su individualidad personal. Sólo cuando el yo está en ese centro, es al mismo tiempo él mismo, es decir, es realmente un yo personal. Por eso, una persona no puede encontrar verdaderamente su identidad hasta que no llegue a vivir en y desde este centro. Es entonces cuando ve todo, incluso lo más insignificante, a la luz del sentido último, porque es capaz de sentir lo que ella misma es y cómo es, de aprehender el mundo sin distorsiones y de vivir conforme a su vocación ${ }^{70}$.

A fin de desplegar esa vida que brota del centro del alma, la persona debe conocerla, lo que equivale a conocerse. No se trata de un conocimiento teórico, sino existencial. Conocer significa entrar en el centro, recogerse en él. Pero hay que tener en cuenta que Edith Stein no concibe el proceso de conocimiento sólo como un recogimiento. Esto podría dar lugar a un quietismo. El autoconocimiento está en función del pleno desarrollo de la persona ${ }^{71}$, por lo que se da de manera progresiva y en distintos grados de profundidad ${ }^{72}$. Cuanto más se acerca al núcleo personal, más se encuentra con su propio ser. "El alma debe 'llegar hasta sí misma' en dos sentidos: conocerse ella misma y llegar a ser lo que ella debe ser. Su libertad participa de estas dos operaciones"73. Sin embargo, la persona no puede llegar por sí misma hasta su centro si no experimenta una llamada desde dentro. Es Dios el que la llama a entrar dentro de $\mathrm{si}^{74}$. El verdadero conocimiento, por tanto, es siempre obra de la gracia ${ }^{75}$.

68 Ibid., p. 1027.

69 Ibid., p. 1030.

70 Cf. STEIN E., Ser finito y ser eterno, op. cit., pp. 1028-1031; STUBBEMANN C.M., op. cit., p. 86.

71 Cf. STUBBEMANN C.M., op. cit., p. 88.

72 Cf. STEIN E., Ser finito y ser eterno, op. cit., pp. 1019-1023

73 STEIN E., Ser finito y ser eterno, op. cit., p. 1019.

74 Cf. STEIN E., Ser finito y ser eterno, op. cit., p. 1032; El castillo interior, op. cit., p. 83; STUBBEMANN C.M., op. cit., p. 89.

75 Cf. STEIN E., Ser finito y ser eterno, op. cit., p. 1032; El castillo interior, op. cit., p.100. 
Además de la oración ${ }^{76}$, la autora distingue diferentes modos de acceder a la interioridad más profunda, los cuales permiten a la persona conectar con su centro para vivir conforme a él. Una posibilidad se da en los sucesos importantes de la propia vida. La persona siente por instantes su alma sin que ésta deje de ser un misterio insondable. Otra posibilidad de conocer el alma en su verdadera profundidad es la voz de la conciencia, que brota del centro del alma. La conciencia no sólo acusa la bondad o maldad de los actos, sino que tiene la función de indicar a la persona el camino hacia su verdadera identidad ${ }^{77}$. También hay un acceso al alma cuando la persona experimenta un aumento de fuerzas más allá de su medida natural, lo que revela la inhabitación del Espíritu de Dios en el alma ${ }^{78}$.

En relación con esto último, comenta: “La gracia mística da como experiencia lo que enseña la fe: la inhabitación de Dios en el alma. Aquel que, guiado por la verdad de la fe, busca a Dios, se dirigirá por libres esfuerzos al lugar preciso al que es atraído por la gracia mística: librándose de los sentidos y de las 'imágenes' de la memoria, y aun de la actividad natural del intelecto y de la voluntad, se retirará a la soledad vacía de su interioridad, para permanecer allí en la fe oscura, en una simple mirada amorosa del espíritu orientada hacia el Dios escondido, quien velado está presente. Aquí perseverará en una paz profunda -porque se halla en el lugar de su reposo- hasta que el Señor quiera transformar la fe en visión. He aquí esbozada en algunos rasgos la Subida del Monte Carmelo, tal como nos lo ha enseñado nuestro padre Juan de la Cruz"79.

Según la fenomenóloga el conocimiento de sí mismo, sea a través de un movimiento consciente hacia su interior, sea a través de la experiencia de su propia finitud, desemboca en el conocimiento de Dios como origen y dador de vida. Pero ella contempla también el camino inverso: ser conocido por Dios le revela al hombre quién es. Con ello pone el imperativo esencial del hombre, llegar a ser él mismo, bajo un nuevo signo: si autoconocimiento significa ser conocido por Dios, la plena realización humana se consigue dejándose guiar por él. Por lo tanto, encontrarse con Dios supone que él toma la iniciativa previa siempre ${ }^{80}$.

Para Edith Stein la grandeza del alma reside en que está llamada a la unión con

76 Cf. STEIN E., Ser finito y ser eterno, op. cit., pp. 1028-1031; El castillo interior, op. cit., p. 105; STUBBEMANN C.M., op. cit., pp. 90-91

77 Cf. STEIN E., Ser finito y ser eterno, op. cit., pp. 1032-1035; STUBBEMANN C.M., op. cit., pp. 91-92.

78 STEIN E., Ser finito y ser eterno, op. cit., p. 1032.

79 Cf. STUBBEMANN C.M., op. cit., p. 94.

80 Cf. STEIN E., Ser finito y ser eterno, op. cit., pp. 1045-1047, 1090. 
Dios $^{81}$. En cuanto espíritu, no sólo es imagen del Espíritu divino, sino que también es capaz de acogerlo, de vivir en plena unión con él. El alma llega en esta unión al grado supremo del ser, es decir, se realiza según su esencia de espiritualidad libre, trascendiéndose en la entrega total a Dios ${ }^{82}$ : "Hemos conocido la interioridad más profunda del alma como la 'morada de Dios'. Por su espiritualidad pura es capaz de acoger en sí al espíritu de Dios; por su libre personalidad puede entregarse de manera como es necesario para esta recepción. La vocación a la unión con Dios es una vocación a la vida eterna. Ya naturalmente el alma humana en cuanto hechura puramente espiritual, no es mortal. En cuanto espiritual y personal, es capaz, por otra parte, de un crecimiento de vida sobrenatural, y la fe nos enseña que Dios quiere ofrecerle la vida eterna, es decir, la participación eterna de su propia vida" 83 .

\section{Vida del espíritu}

El tercer constitutivo que hace posible esta unidad llamada persona humana es el espíritu. "Ser persona quiere decir ser libre y espiritual. Que el hombre es persona: esto es lo que lo distingue de todos los seres de la naturaleza"84. Es decir, dentro del orden de la naturaleza sólo el hombre está dotado de razón, inteligencia, voluntad y libertad.

El alma y el espíritu se diferencian entre sí, aunque no están separados. “El alma es lo oculto e informe" 85 , pero en cuanto forma del cuerpo, ella ocupa el lugar intermedio entre espíritu y materia, propio de las formas de las cosas materiales. En cuanto espíritu, el alma posee su propio ser en sí misma, y es capaz de elevarse por encima de sí misma en libertad personal y de acoger en ella una vida superior, "sin que cese de ser fuente secreta de la vida" ${ }^{86}$. Y mientras "más hondamente el alma se sumerge en el espíritu y más firmemente se instala en su centro, tanto más libremente puede elevarse sobre sí misma y liberarse de las ataduras materiales: hasta romper los lazos que unen el alma y el cuerpo terreno -como sucede en la muerte, y en cierto sentido también en el éxtasis-, y hasta

81 Cf. ibíd., pp. 1051, 1089-1091.

82 Ibíd., p. 1090.

83 STEIN E., La estructura de la persona humana, op. cit., p. 141.

84 STEIN E., El castillo interior, op. cit., p. 106.

85 Ibid., p. 106.

86 Ibid., p. 106 
la transformación del 'alma viviente' en el 'espíritu que da la vida', que es capaz desde sí mismo de formar un "cuerpo espiritual"87.

Al explicar la esencia del espíritu en relación con la Trinidad, Edith Stein señala: "Se ha concebido el ser divino como espiritual. Y si hemos considerado la persona en cuanto soporte de una naturaleza dotada de razón, así su naturaleza espiritual aparece entonces expresada también, pues 'espíritu' y 'razón' parecen convenir uno al otro inseparablemente. Ahora bien ¿qué significa 'espíritu'?... Hemos designado lo espiritual como lo no espacial y no material; como lo que posee un 'interior' en un sentido completamente no espacial y permanente 'en sí', en cuanto sale de sí mismo. Este 'salir de sí' le es de nuevo esencialmente propio: no como si no tuviera un 'en sí', sino porque entrega enteramente su él mismo sin perderlo, y en esta entrega se manifiesta enteramente -en contraposición a la soledad anímica. En la entrega de sí total de las personas divinas, en la cual cada una se enajena enteramente de su esencia y, sin embargo, la conserva perfectamente, cada una está enteramente en sí misma y enteramente en las otras, tenemos ante nosotros el espíritu en su realización más pura y perfecta. La divinidad trina es el verdadero 'reino del espíritu', simplemente lo 'supraterreno'. Toda espiritualidad o capacitación del espíritu por parte de las criaturas significa una 'elevación' en este reino, aunque en sentidos diferentes y diversas maneras" 8 .

"El espíritu es lo libre que fluye de dentro, la vida que se manifiesta" 89 , y como tal le descubre al hombre el mundo exterior, hace posible su acceso a otros espíritus y está al servicio de su desarrollo personal; más aún, le permite abrirse al espíritu absoluto, Dios mismo, y entrar en plena comunión con él.

El hombre sale de sí mismo con su vida espiritual y entra en el mundo que se le abre para actuar en él de forma personal-espiritual, sin abandonarse a sí mismo. Esta intervención en el mundo no significa un mero contacto exterior con los objetos. Gracias al espíritu, es decir, gracias a su capacidad de compenetrarse con el espíritu ajeno, sea subjetivo u objetivo, el individuo entiende el sentido de lo que le rodea y es capaz de comunicar su propio ser a través de acciones creativas. Aquí es importante considerar que Edith Stein no delimita el reino del espíritu sólo al espíritu personal, sino a todo el mundo creado. De esta manera,

87 STEIN E., Ser finito y se eterno, op. cit., pp. 956-957.

88 STEIN E., El castillo interior, op. cit., p. 106.

89 Cf. STUBBEMANN C.M., op. cit., pp. 98-99. 
cuando el hombre acoge en sí los valores espirituales que contiene el mundo, estos se convierten para él en fuente de fuerza anímico-espiritual ${ }^{90}$.

Según nuestra autora, la vida espiritual es actualidad del ser. En el alma humana esta actualidad no se da desde el principio de su existencia, ya que la vida espiritual comienza con el despertar de la razón y se va realizando progresivamente ${ }^{91}$. Como la vida espiritual consciente constituye el nivel más alto de actualidad y con ello el modo supremo de ser del núcleo de la persona, y dado que la vida espiritual implica necesariamente el ejercicio de la libertad personal de cada uno, la persona humana se encuentra frente a una insoslayable responsabilidad: la de fomentar su vida espiritual, lo que equivale a un aumento del ser en sentido de su actualización más personal, o la de su aniquilamiento parcial o total. Esta responsabilidad radica en último término en que el hombre, un ser finito, creado a imagen de Dios, es llamado a reflejar en su unicidad e individualidad un rayo de la esencia divina ${ }^{92}$. Y Dios es plenitud del ser. Ya que la existencia humana es don, el sí o no del hombre a su propia naturaleza y vocación se convierte así en un sí 0 no frente al Creador, en un abrirse o cerrarse frente al ser ${ }^{93}$.

Ya vimos que cuanto más recogida vive la persona en el centro del alma, más radicalmente lleva su comportamiento el sello de su peculiaridad personal, es decir, más llega a ser ella misma. A través de esta plenitud personal, sin embargo, el hombre no sólo refleja la imagen de Dios, en el que encuentra su imagen originaria toda vida espiritual ${ }^{94}$; en su más profundo centro la persona está además abierta a él. Por lo tanto, gracias al espíritu, la persona no sólo es capaz de llegar al centro del alma, que por ser lo más espiritual es también reflejo más auténtico del espíritu divino, sino que en este centro está constitutivamente abierta al espíritu absoluto. Aquí se produce el cambio del punto de vista de la persona: ya no se mira a sí misma, sino que dirige la mirada simple y amorosa del espíritu al Dios escondido que está ocultamente presente. Puesto que apertura del espíritu significa salir de sí, entregarse sin perderse, a imagen de la Trinidad, la apertura constitutiva del espíritu humano frente al espíritu divino implica al mismo tiempo una llamada a la unión con é ${ }^{95}$.

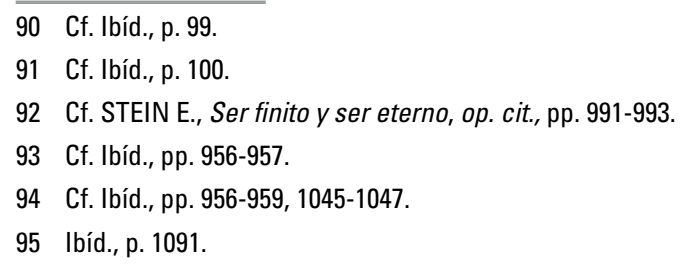


Sobre esta unión la fenomenóloga afirma: “Debemos reflexionar también en lo que significa el recibir a Dios en la interioridad más profunda del alma... Está presente en las moradas exteriores del alma, donde ella misma no nota nada de la presencia de Dios y está presente en su interioridad, aun cuando ella no está dentro de sí. Así, pues, no se puede decir que Dios viene a un lugar en el que no estaba antes"96. El hecho de que Dios sea acogido en el alma significa que ésta se abre libremente a él y que se entrega a esta unión de una manera que sólo es posible entre personas espirituales. "Se trata de una unión de amor. Dios es el amor y la participación en el ser divino, que garantiza la unión, debe ser una participación en el amor"97.

De este modo, para Edith Stein, la plena madurez humana culmina en la unión del hombre con Dios. Esto sólo se comprende profundamente a la luz de la fe, es decir, a la luz del misterio según el cual el hombre lleva en sí la imagen de la Trinidad.

\section{CONCLUSIÓN}

Este estudio nos permite apreciar los aspectos principales de la antropología de Edith Stein en Ser finito y ser eterno. Desde el principio se distinguen dos categorías fundamentales en su pensamiento, que son naturaleza y espíritu. De ellas sólo el hombre participa gracias a su unidad corporal-anímico-espiritual. Nuestra autora concibe al ser humano como una unidad de cuerpo vivo, alma y espíritu. Los tres elementos, reunidos en un sujeto de manera substancial, conforman el fenómeno humano denominado persona. A lo largo de la obra se esclarecen las características y relaciones de estos tres constitutivos, que confluyen en la vida interior de la persona, aunque de manera diferenciada.

Queda en evidencia el significado profundo y trascendental del núcleo o alma de la persona humana. Lo íntimo del alma es para Edith Stein la última profundidad de la persona, quizá sólo tácitamente sospechada por ésta. Este centro del alma coincide con la esencia de la persona, con su individualidad personal. El concepto de espíritu como apertura confiere al hombre un puesto especial en la naturaleza, frente al mundo y de cara a Dios. Gracias a su espíritu sólo el hombre es capaz de comunicarse con otros sujetos, de intervenir creativamente en el mundo y de llegar

96 Ibid., p. 1091.

97 Cf. STEIN E., Ciencia de la cruz (Obras completas, Vol. V: Escritos espirituales. En el Carmelo Teresiano: 1933-1942), Burgos, 2004. , p. 334. 
a la unión con Dios. En ello se cifra al mismo tiempo su madurez y su plenitud. Así, el espíritu se manifiesta como la condición necesaria para el acceso del hombre al ámbito de la trascendencia y de la vida de la gracia. El alma humana, por su parte, es espiritual en cuanto procede del acto creador de Dios que la hizo a su imagen y semejanza. Ella es conducida por la gracia a partir del momento mismo del acto creador de Dios -y esto no sólo desde fuera, sino desde su misma interioridad (corazón)-, desde la realidad finita hacia el ser eterno, donde alcanza la plenitud de su ser.

La vida interior de la persona se revela en esta obra como un mundo complejo que se puede recorrer y profundizar hasta llegar a su más profundo centro, aquel que define al hombre. En ese mundo interior la persona se encuentra con el mundo exterior, consigo misma y con Dios. De esta manera, la interioridad nos ofrece una clave fundamental para comprender la esencia de la persona.

\author{
María Teresa GREENE \\ Magíster (C) Teología \\ PUC - Santiago \\ mtgreene@uc.cl
}

